\title{
Using Geospatial Information Technology for Rural Agricultural Development Planning in the Nebo Plateau, South Africa
}

\author{
Brilliant Petja ${ }^{1,2}$, Edward Nesamvuni ${ }^{3}$ \& Albertina Nkoana ${ }^{4}$ \\ ${ }^{1}$ Directorate of Research, Limpopo Department of Agriculture, Polokwane, South Africa \\ ${ }^{2}$ Risk and Vulnerability Science Centre, University of Limpopo: Turfloop Campus, Sovenga, South Africa \\ ${ }^{3}$ Office of the Registrar, University of Venda, Thohoyandou, South Africa \\ ${ }^{4}$ Department of Plant Production, Soil Science and Agricultural Engineering, University of Limpopo, Sovenga, \\ South Africa \\ Correspondence: Brilliant Petja, Risk and Vulnerability Science Centre, University of Limpopo: Turfloop \\ Campus, Private Bag x1106, Sovenga 0727, South Africa. Tel: 27-15-294-3208. E-mail: petjamb@gmail.com
}

Received: November 13, 2013 Accepted: December 21, 2013 Online Published: March 15, 2014

doi:10.5539/jas.v6n4p10

URL: http://dx.doi.org/10.5539/jas.v6n4p10

\begin{abstract}
This study uses geospatial technologies (remote sensing and geographic information system) to assess the agricultural potential of the Nebo Plateau, a rural area in the Limpopo Province of South Africa. This approach entails assessing the suitability in terms of land/soil and climate, which are determinant factors for agricultural development. The environmental requirements of selected crops were analyzed using $\operatorname{ArcView}^{\text {TM }}$ GIS. Various spatial analysis techniques were used to model and assign classes of suitability based on the most important and yield-limiting parameters such as rainfall, temperature and soil characteristics. Results indicate that the area is potentially suitable to a variety of agricultural commodities where $65 \%$ of the area is suitable for cultivation. This is however considerate of environmental and climatic constraints such as the availability of water for irrigation, improvement of the state of the environment, prevention of soil degradation due to erosion and compaction, improvement of soil fertility by means of sound farming and management practices. These outputs are presented within a user friendly GIS platform for a better decision support to the development agencies and government. The results also help to provide inputs for assessing financial feasibility of farming projects. This study therefore emphasizes the importance of geospatial technologies in informing and promoting sustainable agricultural development.
\end{abstract}

Keywords: geospatial technologies, agricultural potential, rural, sustainable agricultural development

\section{Introduction}

Limpopo Department of Agriculture (LDA) commissioned the development of a Provincial Agricultural Development Strategy in 2004. This strategy responded to a national call for a coordinated and effective rural development that will become sustainable. It advocates for re-establishment of agriculture as an important contributor to the rural economy in a sustainable fashion that will not compromise the environment (EnviroGIS \& ARC, 2007). Agriculture as a sector, contributes significantly to the sustenance and livelihoods of rural communities. This study is conducted in a rural area of Nebo at Sekhukhune District of Limpopo Province. LDA is currently spearheading the revival of agricultural production in Sekhukhune through agricultural hubs development programme.

An agricultural hub as per agricultural development strategy (EnviroGIS \& ARC, 2007), refers to a concentration of agricultural enterprises, which include amongst others projects within the value chain such as agricultural production, agro industries, value adding services and marketing. The development may include a variety of implementation models, which may vary from establishment of small scale farmers as entrepreneurs, commercial units and also investment by foreign business. This is aimed at supporting participation of agriculture in the mainstream economy. The geo-physical location should be on good land with at least medium to high land capability, with available water bodies and other institutions that could support the development of the hub. The Nebo Plateau Agricultural Hub is therefore such a focal area which aims at putting agriculture in its place as a contributor to the rural economy. Nebo is a high potential agricultural production area. The area 
consists of approximately 10000 ha of land which if managed effectively can have a significant contribution to rural development. This justifies the need to assess and characterize different agricultural areas at farm level to evaluate their agricultural development potential and manage them according to their capability. According to the district Integrated Development Plan, Sekhukhune is one of the poorer districts in the province with an unemployment rate of about $65 \%$ where $77.4 \%$ of the households receive below the minimum income level of $\mathrm{R}$ 1100 (rands) per annum. Despite relative abundance of agricultural resources, only $1.2 \%$ of the households depend on the sales of farm produce as their only source of income, while $38 \%$ depends on pensions and social grants (Greater Sekhukhune District Municipality, 2005). A need was therefore identified to use geoinformatics tools validated with field data to assess a natural resource potential for agricultural development.

The purpose of this study is to demonstrate the importance of using Geographic Information System (GIS) and Remote Sensing (RS) in supporting decisions for sustainable agricultural development. This is experimented within a rural setting where use of such technology is limited, despite having been used elsewhere in developed and developing nations.

\section{The Role of GIS and Remote Sensing in Agriculture}

Sustainable agriculture and rural development (SARD) practices have potential to reduce hunger and poverty while sustaining the ecosystems that poor rural people rely on for livelihoods (International Institute for Sustainable Development, 2010). Because of lack of research, rural areas face challenges related to agricultural sustainability, natural resource management, business diversification, agriculture efficiency, and long term growth and planning (Ohio Geospatial Program: Agriculture and Natural Resources, 2003). Sustainable agricultural productivity in the 70s was not a major issue as food resources did not appear to be threatened. The attention was on producing enough food to overcome the immediate problems of food deficit. However, the environmental effects of intensive agriculture, such as soil erosion, salinization, pollution of ground and surface water, and loss of biodiversity resulted due to land that was not utilized according to its sustainable potential that ultimately led to the concerns of sustainability of agricultural production challenges at global and national scale (FAO, 1995). Sustainable agriculture involves efficient and effective management of environmental, economic and social aspects. Moreover, it involves dynamic interactions between technology, environment and society. The challenge for agricultural research systems' management in the 21st century is to enable the transition to sustainable agricultural development through functional integration of the sustainability concept into agricultural research policies, programmes and projects (Parris \& Kates, 2003; Clark \& Dickson, 2003). This challenge can be overcome through utilizing geospatial information technologies (Wikipedia, 2010).

GIS has proved to be an efficient and effective tool for spatial analysis and management of natural resources. GIS is a specialized branch of geo-spatial information technology that helps store, manage and analyse geographically referenced data. Remote sensing data collection systems such as aerial photographs and satellites provide periodic land use, land cover and other thematic information (Deichmann \& Wood, 2001). GIS, Global Positioning System (GPS) and image processing software systems for processing RS data, form basic components of the geo-spatial information technology. These geo-spatial technologies are the foundations for precision farming, a paradigm shift in agriculture (Mandal \& Ghosh, 2000). Geo-spatial decision support systems are based on variability of crops, soils and other related factors. A study reported by Bobade et al. (2010) in Seoni district of Madhya Pradesh, India on land evaluation for agricultural planning was carried out based on soil survey data incorporating a GIS technology. The soil-based GIS data was compiled and interpreted for land use suitability and fertility assessment for Seoni district. Maps of fertility and land use suitability were generated from geographical information system records. A suitability map for each agricultural land use was developed by combining the climatic and soil site factors for each crop in the study area using precision agriculture approaches. They found the use of geospatial technology to be of great importance in farm production planning and decision support. Presently, geo-spatial information technologies are becoming increasingly important in the decision-making process of land management planning. GIS coupled with satellite data provides decision-makers with a unique view of the landscape that enables land managers to improve natural resource management. The use of geo-spatial information establishes a dialogue linking local knowledge and science, together with national development strategies. One general advantage of geospatial data is the capability to increase the accuracy of data gathering and analysis (Blaschke, 1999). These technologies have been widely used successfully to manage land-related resources in most of the advanced industrialized countries. The increasing availability of remote sensing images, acquired periodically by satellite sensors on the same geographical area, makes it extremely interesting to develop the monitoring systems capable of automatically producing and regularly updating land cover maps of the considered site (Bruzzone et al., 2002). Naesset (1997) reported on the use of GIS technology as a decision support tool for the preservation of forest biodiversity in Norway. Better 
assessment of the changes of land cover by using digital analysis of remote sensing satellite data help decision makers to develop effective plans for sustainable management of land (Gordon, 1980; Milington et al., 1986; Franchek \& Biggam, 1992). Policy issues on natural resources and agriculture in South Africa rely mostly on information obtained from the scientific community. Such information is incorporated with data obtained from various social science sectors to derive policy decisions. Remote sensing has been used as a tool for monitoring natural resources and for agricultural applications in South Africa. It has been used in a policy oriented approach to provide information to influence development decisions (Petja et al., 2004).

\section{Methodology}

\subsection{Study Area}

The study area is situated in the Greater Sekhukhune District Municipality of Limpopo Province (Figure 1).

\subsection{Data Collection}

This study used a combination of both primary and secondary data acquisition approaches. Long term environmental and climate data were acquired from the Agricultural Research Council - Institute for Soil, Climate and Water in a GIS format (ARC-ISCW, 2008). Although usable to some extent for decision support, most data was processed to a national scale and as such subject to coarse resolution. This therefore warranted collection of field data to verify and validate such data at a local and farm scale. Other topographic data was acquired from the Department of Rural Development and Land Reform. Because of the bigger extent of the area in question, several consultants were appointed to assist the department in conducting field surveys and analyses to correct the national vector data to a local scale. EnviroGIS, NRM Consulting and PriceWaterhouseCoopers were appointed to assist with such a task at a shorter time period, so that development decisions can be arrived at and implemented timeously. The initial stage in conducting field surveys included the identification of the variables needed to assess agricultural potential at a farm scale. The variables involved the state of natural resources and environmental parameters, which cover amongst others the areal extent of arable land available, climatic situation, soil analysis and crop suitability. Farm boundaries were demarcated using GPS for easy integration into a GIS system. Data on the previous and current land use were acquired from the departmental archives and satellite images. As a result of analysis of environmental data and resultant crop suitability assessments, it was possible to project the financial requirements and economic viability for establishing agricultural projects.

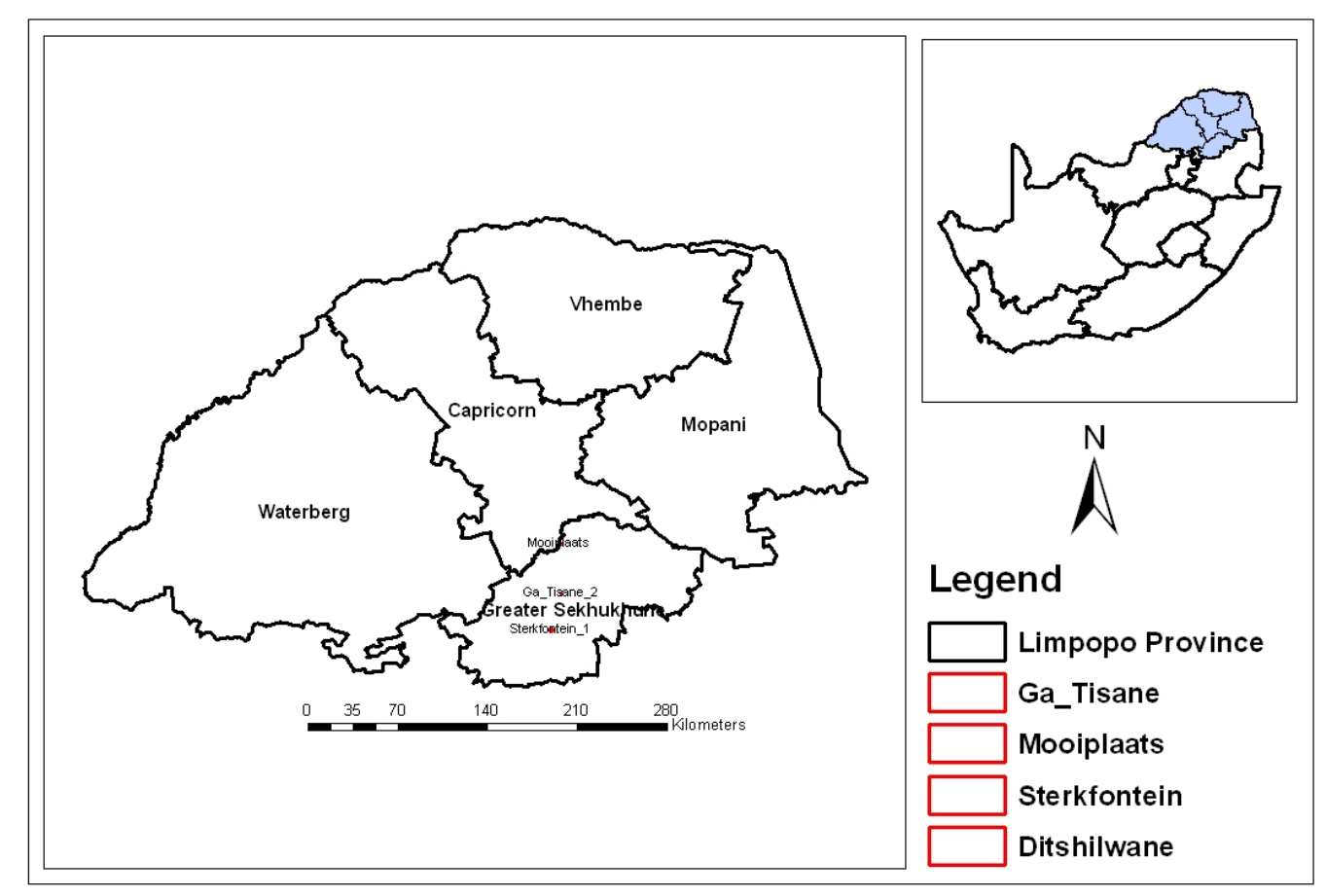

Figure 1. Locality map of the Nebo Agricultural Hub 


\subsection{Data Processing and Analysis}

Geospatial technologies play a significant role in producing suitability maps. These involve using inverse distance weighting techniques and combining different map layers. Base maps were created for each of the farm areas using coordinates acquired during the field survey. These base maps were overlaid with a subset of national soil layer to determine sampling points for a detailed soil survey and field verification. Data from these observations were used to establish the boundaries between the soils thereby demarcating soil units. This verified field data was captured using ArcView ${ }^{\circledR}$ GIS software. Soil unit boundaries were delineated as areas that are relatively homogenous with respect to soil form and family, total soil depth and effective soil depth, slope gradient, slope shape, climate (rainfall and temperature) and lithology. The soil units as represented on the soil maps were used to define suitability of different crops. Land capability was determined for both the dominant and sub-dominant soils at each of the farms based on climate data, soil physical and chemical properties and environmental risks for each of the crops. Land use maps were extracted from the National Landcover 2000 database which was generated using Landsat Thematic Mapper. Long-term mean monthly rainfall and temperature surfaces were created using ArcView. Rainfall totals were interpolated between the stations and a filter was used over the interpolated surfaces to create a smooth trend surface. Multiple regression equations were used to estimate the difference between the actual mean rainfall at each station and the value approximated by the trend surface. These multiple regression equations utilized parameters such as rain shadow, standard deviation of elevation points, distance from the ocean and altitude. The difference surfaces obtained through the use of the multiple regression equations were added to the trend surface to obtain the final surface for each month. For each soil unit, financial analysis was conducted per crop based on normal agronomic practices. The results are analysed at farm level for Ditshilwane, Sterkfontein, Ga Tisane and Mooiplaats respectively.

\section{Results and Discussion}

\subsection{Land Capability and Climate}

The Nebo Plateau area is considered to be marginal for cultivated agriculture. Certain areas are however highly suitable if an adequate supply of water for irrigation is possible. Approximately $34 \%$ of the area that has been assessed $(1,370 \mathrm{ha})$ is suitable only to natural and/or planted pastures. The remaining area $(2,642 \mathrm{ha})$ is potentially suitable to horticulture as well as grain and oil seed production. The main environmental constraint is the state of the natural vegetation and low biodiversity of the area. The ecosystem is regarded as highly degraded with evidence of severe erosion and over-utilization of the land. The sandy nature of most of the soils contributes negatively to an increased risk to erosion. The hydrology of the area is considered sensitive to cultivated agricultural practices. The main climate risk is the low annual rainfall coupled with high potential evaporation in some areas which may not be suitable for dryland production. The average annual rainfall received ranges from $619-631 \mathrm{~mm}$ with the mean average annual temperature of $20^{\circ} \mathrm{C}$. The area has a mean average growing season of about 167 days considerate of $27.5 \%$ of rainfall coefficient variance. The high evaporation risk results in low moisture supply capacity. Irrigation is therefore essential for cultivated farming practices (EnviroGIS, 2009). Figure 2 shows the overall land capability for the whole municipality. In the municipality, 18,000 ha is suitable for dry-land cultivation whereas 45,000 ha suitable for irrigation. The Nebo Plateau constitute about 10000 ha of arable land in the area.

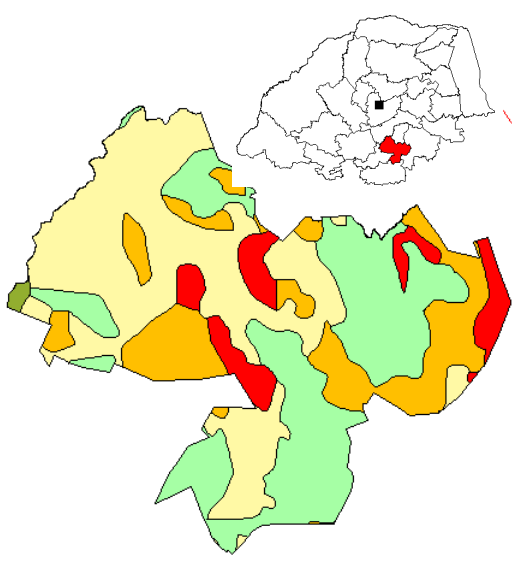

\begin{tabular}{|l|r|}
\hline \multicolumn{1}{|c|}{ Description } & Area (ha) \\
\hline Very Low & $16,734.46$ \\
\hline Very low - Low & $41,567.63$ \\
\hline Low & $80,121.57$ \\
\hline Low-Moderate & $70,373.40$ \\
\hline Moderate & 897.79 \\
\hline Moderate - High & 0.00 \\
\hline High & 0.00 \\
\hline High - Very high & 0.00 \\
\hline Very High & 0.00 \\
\hline Total: & $\mathbf{2 0 9 , 6 9 4 . 8 5}$ \\
\hline
\end{tabular}

Figure 2. Land capability classes for makhuduthamaga 


\subsection{Soils and Land Use}

Figures 3 to 6 show the land use and soil form for the selected farms in the Nebo Plateau. The land use shows the current activities on the land extracted from the satellite imagery and verified in the field. The soil map shows demarcated soil forms in the farm extracted from the national database and further validated with field surveys to improve the mapping scale. Different soil units reflected on the soil map represents suitability for different crops when taken into consideration with climate data.
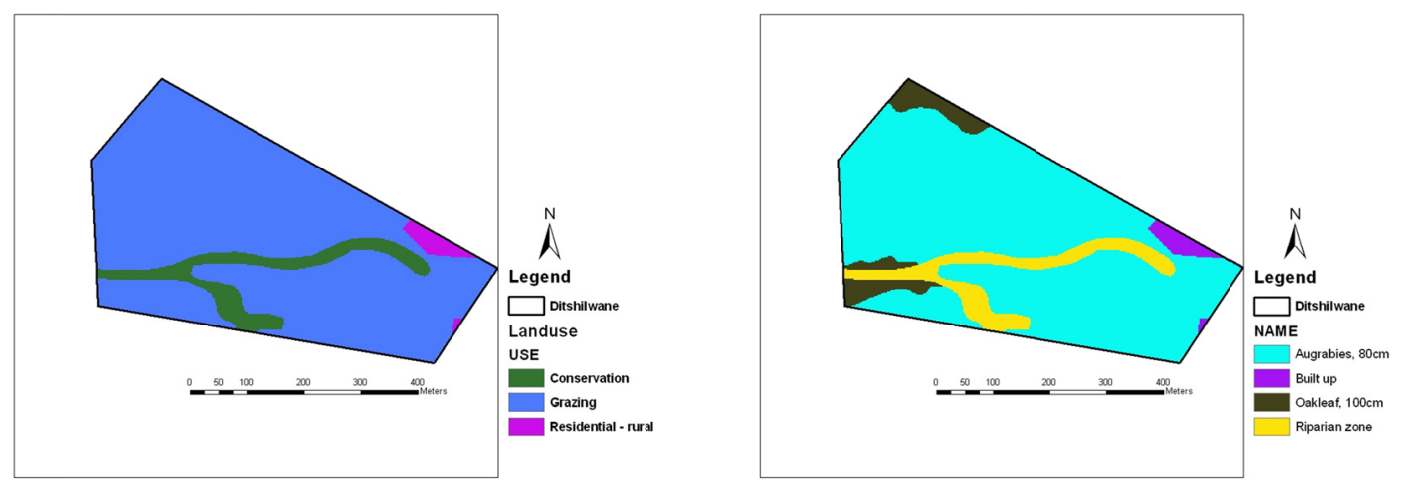

Figure 3. Land use and soil maps for Ditshilwane
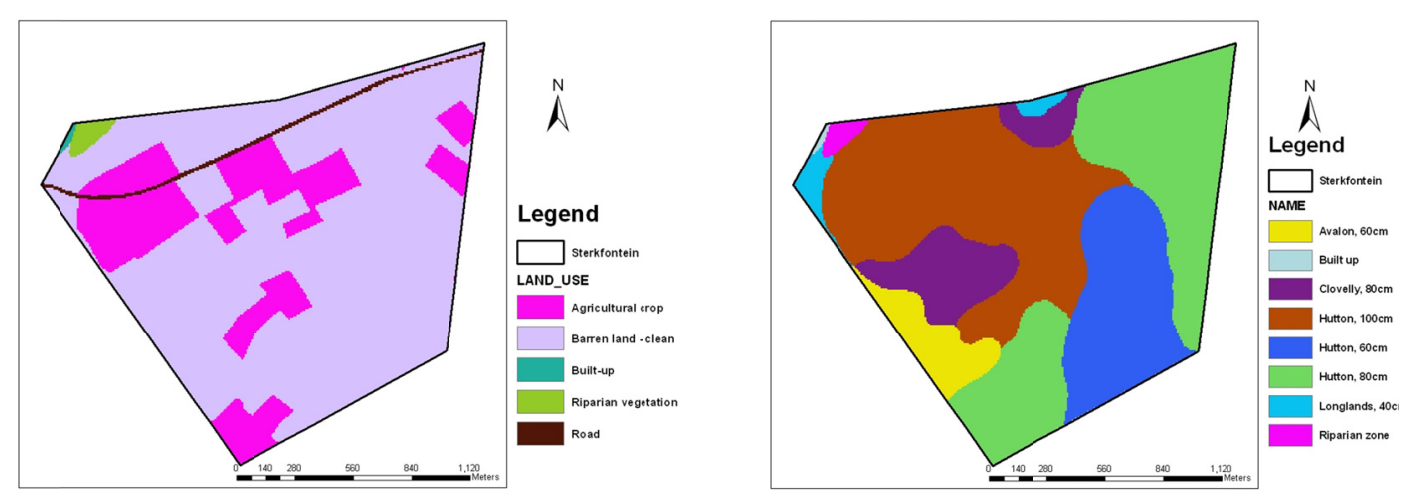

Figure 4. Land use and soil maps for Sterkfontein
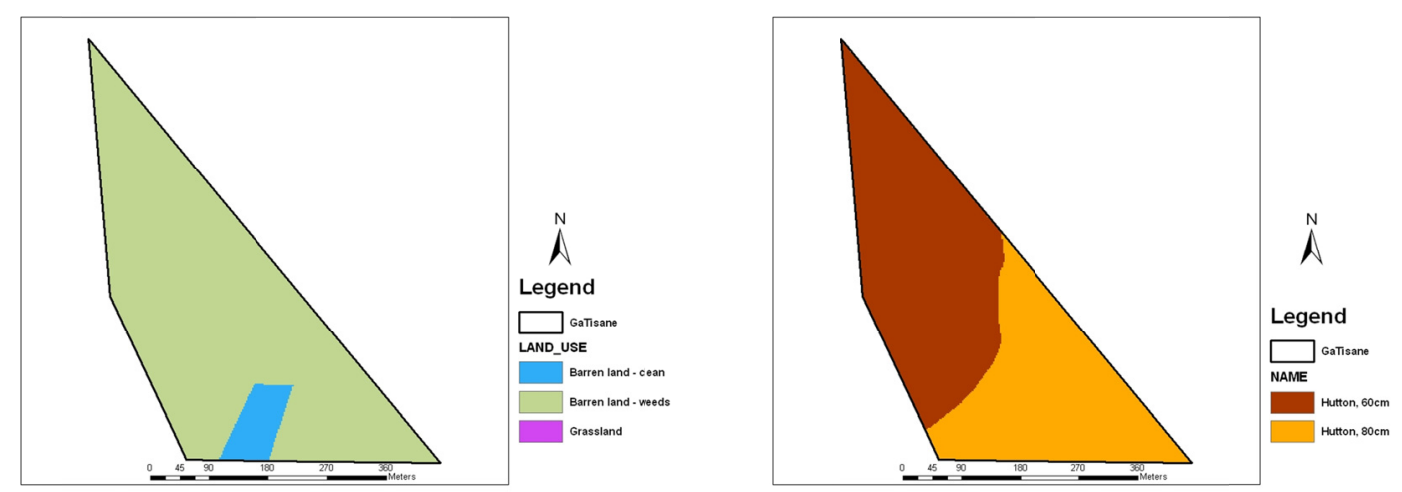

Figure 5. Land use and soil maps for Ga Tisane 

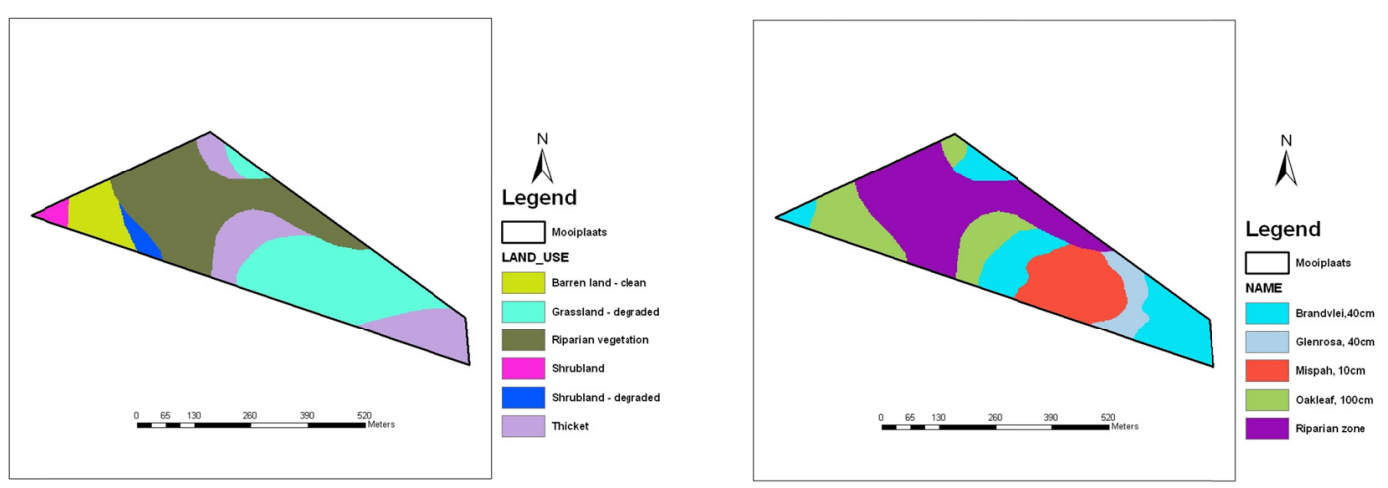

Figure 6. Land use and soil maps for Mooiplaats

\subsection{Crop Suitability}

Table 1. Potato suitability

\begin{tabular}{lll}
\hline Suitability & Area (ha) & Percentage \\
\hline Optimal & 2829.25 & 70.35 \\
Unsuitable & 382.78 & 9.52 \\
Unsuitable-Marginal & 809.47 & 20.13 \\
\hline Total & 4021.5 & 100 \\
\hline
\end{tabular}

Table 2. Tomato suitability

\begin{tabular}{lll}
\hline Suitability & Area (ha) & Percentage \\
\hline Optimal & 219.82 & 5.47 \\
Suitable & 2658.66 & 66.11 \\
Unsuitable & 333.54 & 8.29 \\
Unsuitable-arginal & 809.47 & 20.13 \\
\hline Total & 4021.5 & 100 \\
\hline
\end{tabular}

Table 3. Maize suitability

\begin{tabular}{lll}
\hline Suitability & Area (ha) & Percentage \\
\hline Marginal & 1255.13 & 31.21 \\
Marginal - Suitable & 828.34 & 20.6 \\
Suitable & 809.67 & 20.13 \\
Suitable-Optimal & 382.59 & 9.51 \\
Unsuitable & 10.76 & 0.27 \\
Unsuitable-Marginal & 735.01 & 18.28 \\
\hline Total & 4021.5 & 100 \\
\hline
\end{tabular}


Table 4. Groundnuts suitability

\begin{tabular}{lll}
\hline Suitability & Area (ha) & Percentage \\
\hline Marginal & 1299.86 & 32.32 \\
Suitable & 1529.38 & 38.03 \\
Suitable-Optimal & 49.24 & 1.22 \\
Unsuitable & 333.54 & 8.29 \\
Unsuitable-Marginal & 809.47 & 20.13 \\
\hline Total & 4021.5 & 100 \\
\hline
\end{tabular}

A variety of crops were deemed suitable in the Nebo Plateau which may be subject to crop rotation or different forms of management. The suitability per each commodity is linked to a specific soil unit and the corresponding climatic situation. In some areas, there are recommendations for irrigation. Table 1 shows the suitability for potato production. Conditions at Nebo are highly suitable to potato production, mainly due to favourable temperatures. Soil preparation and cultivar choice are however critically important towards successful potato production. Table 2 shows the suitability for tomatoes. The temperatures at Nebo are considered favourable for tomato production. Approximately $70 \%$ of the area is suitable looking at both soils and climate. Irrigation at soils with optimal properties is however essential. Table 3 represents maize suitability in the area. About $30 \%$ of the area is considered suitable $(>=3.5 \mathrm{t} / \mathrm{ha}$ ) for dry land production with good management practices and $50 \%$ marginal $(>=1.5 \mathrm{t} / \mathrm{ha})$. Yield will increase with irrigation on good soils. Table 4 shows the suitability for groundnuts. About $40 \%$ of the area is suitable for groundnut production. It is recommended that they should be rotated with other crops.

\subsection{Economic Feasibility}

For calculation of financial models to ensure profitable farming practices, financial projections are linked at a commodity level which is derived from its suitability with reference to a soil unit (Figures 3 to 6). A comprehensive financial analysis for each farm portion was conducted. These generated the total financial requirements for establishment of each agricultural project at farm level, providing sufficient direction for government budgetary considerations. This financial analysis include the needs to develop irrigation systems, prepare land, fence the land and develop basic farm building structure as sheds, offices and/ or store rooms. The Net Present Value (NPV) was also calculated and the investment costs are included which demonstrate in some cases that the Internal Rate of Return (IRR) is at least equal to the cost of capital. In such cases recommendations are that the outstanding investment costs be covered by grant finance or any similar development support. Projects which demonstrate sound financial viability are immediately recommended for implementation and investment may therefore be attracted.

\section{Conclusions}

Rural areas are the most underdeveloped and poverty stricken in South Africa despite the fact that some of them are rich in natural resources. Under-development in these areas could be to some extent attributed to exclusive separate development policies of the past. Since establishment of the new democratic government in South Africa, focus shifted to the development of rural areas. This study showed how geospatial technology could contribute to informing efficient rural agricultural development. It provides an opportunity for holistic assessment of natural resources to inform sustainable agricultural development. Based on the site specific characteristics, it is possible to recommend particular crops and agricultural management practices that will contribute to the betterment of the rural economy. Within the context of rural South Africa, a geospatial technology approach provides a decision support platform to encourage implementation of sustainable agricultural development solutions. This demonstrates their importance in informing successful implementation of policy.

\section{Acknowledgement}

The authors acknowledge the use of data obtained from Agricultural Research Council, and Limpopo Department of Agriculture through contracting NRM Consulting and EnviroGIS. The national Department of Agriculture, Forestry and Fisheries is acknowledged for funding the archive and maintenance of the spatially referenced natural resource data at ARC-ISCW. Limpopo Department of Agriculture is thanked for the support on conducting feasibility studies for rural agricultural development. 


\section{References}

ARC-ISCW. (2008). Natural Resource Databases. ARC-Institute for Soil, Climate and Water, Pretoria.

Blaschke, T. (1999). Sustainability with GIS towards a proactive nature conservation approach. Retrieved July 27, 2010, from http://www.sbg.ac.at/geo/people/tblaschke/publications/sustain_abs.html

Bobade, S. V., Bhaskar, B. P., Gaikwad, M. S., Raja, P., Gaikwad, S. S., Anantwar, S. G., .. Maji, A. K. (2010). A GIS-based land use suitability assessment in Seoni district, Madhya Pradesh, India. International Society for Tropical Ecology, 51(1), 41-54.

Bruzzone, L., Cossu, R., \& Vernazza, G. (2002). Combining parametric and non-parametric algorithms for a partially unsupervised classification of multitemporal remote sensing images. Information Fusion, 3, 289-297. http://dx.doi.org/10.1016/S1566-2535(02)00091-X

Clark, W. C., \& Dickson, N. M. (2003). Sustainability science: The emerging research program. Proceedings of the National Academy of Sciences, 100, 8059-8061. http://dx.doi.org/10.1073/pnas.1231333100

Deichmann, U., \& Wood, S. (2001). GIS, GPS, and Remote Sensing, Brief 7 of 9. 2020 Focus 7 (Appropriate Technology for Sustainable Food). International Food Policy Research Institute (IFPRI). Retrieved July 26, 2010, from http://www.ifpri.org/2020/focus/focus07/focus07_07.htm

EnviroGIS, \& ARC. (2007). Limpopo Agricultural Development Strategy. EnviroGIS Pty Ltd, Pretoria.

EnviroGIS. (2009). Crop Suitability, Crop Rotation Scheduling and Land Use Planning: Nebo Agricultural Hub. EnviroGIS Pty Ltd, Pretoria.

FAO. (1995). World Agriculture Towards 2010. In N. N. Alexandratos (Ed.), FAO Study. Rome, Italy: FAO.

Fassio, A., Giupponi, C., Hiederer, R., \& Simota, C. (2005). A decision support tool for simulating the effects of alternative policies affecting water resources: an application at the European scale. Journal of Hydrology, 304, 462-476. http://dx.doi.org/10.1016/j.jhydrol.2004.07.048

Franchek, R. J., \& Biggam. P. F. (1992). Using USDA Soil Conservation Service County Soils Data with a Geographic Information System: Geographic Information Systems and Mapping Practices and Standards, ASTM STP 1126 (pp. 115-121). In A. I. Johnson, C. B. Pettersson, \& J. Fulton (Eds.). Philadelphia: American Society for Testing and Materials.

Gordon, S. (1980). Utilizing Landsat imagery to monitor land use change: A case study in Ohio. Remote Sensing of Environment, 9, 189-196. http://dx.doi.org/10.1016/0034-4257(80)90028-0

Greater Sekhukhune District Municipality. (2005). The Integrated Development Plan: 2005-2008. Greater Sekhukhune District Municipality, Groblersdal.

International Institute for Sustainable Development. (2010). Sustainable Agriculture and Rural Development (SARD) Initiative. $\quad$ Retrieved July 27, 2010, from http://www.iisd.org/measure/gov/sd_strategies/national.asp

Mandal, D., \& Ghosh, S. K. (2000). Precision farming - The emerging concept of agriculture for today and tomorrow. Current Science, 79, 1644-1647.

Milington, A. C., Jones, A. R., Quarmby, N. A., \& Townsend, J. R. G. (1986). Monitoring geomorphological processes in desert marginal environments using multitemporal satellite imagery. Proceedings of the International Symposium on Remote Sensing for Resource Development and Environmental Management, A. A. Balkema.

Naesset, E. (1997). Geographical Information systems in long-term forest management and planning with special reference to preservation of biological diversity: a review. Forest Ecology and Management, 93, 121-136. http://dx.doi.org/10.1016/S0378-1127(96)03928-X

Ohio Geospatial Program: Agriculture and Natural Resources. (2003). MAP@SYST: Promoting the diversified use of geospatial technologies (GPS, GIS, and Remote Sensing) for addressing community, agricultural, and environmental issues. Agriculture and natural resources, Ohio.USA. Retrieved July 27, 2010, from http://geospatial.osu.edu/education/map@syst.html

Parris, T. M., \& Kates, R. W. (2003). Composite indicators of environmental sustainability. Annual Revision of Environmental Resourses, 28, 13.1-13.28. 
Petja, B. M., Annegarn, H. J., \& Newby, T. S. (2004). A South African Approach for using Remotely Sensed Data to Influence Policy Decisions (pp. 605-608). Proceedings of the 2004 IEEE-International Geoscience and Remote Sensing Sysmposium, Anchorage.

Roberts, A. M., \& Moore, R. V. (1998). Data and databases for decision support. Hydrological Processes, 12, 835-842. http://dx.doi.org/10.1002/(SICI)1099-1085(199805)12:6<835::AID-HYP657>3.3.CO;2-G http://dx.doi.org/10.1002/(SICI)1099-1085(199805)12:6<835::AID-HYP657>3.0.CO;2-P

Wikipedia. (2010). Geospatial Technology. Retrieved July 27, 2010, from http://en.wikipedia.org/w/index.php?title=Geospatial_technology\&oldid=336255930

\section{Copyrights}

Copyright for this article is retained by the author(s), with first publication rights granted to the journal.

This is an open-access article distributed under the terms and conditions of the Creative Commons Attribution license (http://creativecommons.org/licenses/by/3.0/). 